This is an electronic reprint of the original article. This reprint may differ from the original in pagination and typographic detail.

Author(s): Fortunati, Leopoldina; Taipale, Sakari

Title: $\quad$ Organization of the social sphere and typology of the residential setting in Europe: how sociability affects the adoption of the mobile phone in rural and urban locations

Year: $\quad 2012$

Version:

Please cite the original version:

Fortunati, L., \& Taipale, S. (2012). Organization of the social sphere and typology of the residential setting in Europe: how sociability affects the adoption of the mobile phone in rural and urban locations. Technology in Society, 34(1), 33-43.

https://doi.org/10.1016/j.techsoc.2011.12.004

All material supplied via JYX is protected by copyright and other intellectual property rights, and duplication or sale of all or part of any of the repository collections is not permitted, except that material may be duplicated by you for your research use or educational purposes in electronic or print form. You must obtain permission for any other use. Electronic or print copies may not be offered, whether for sale or otherwise to anyone who is not an authorised user. 


\section{Organization of the social sphere and typology of the residential setting in Europe: how sociability affects the adoption of the mobile phone in rural and urban locations}

\section{Introduction}

The purpose of this study is to explore how the organization of the relational sphere at a social level in different geographical settings is associated with the possession of a mobile phone. The issues we want to investigate are: first, the relation between the possession of a mobile phone and the urban or rural life and, second, the relation between the organization of the social sphere and the possession of a mobile phone in rural and urban settings. The first issue rises from the need to clarify ambivalent and even contradictory results coming from various waves of studies addressing the question of the relationship between ICTs (information and communication technologies), in particular the mobile phone, and the rural/urban environment [1] and [2] and [3]. A first wave of studies showed a correlation between the urban setting and the diffusion and appropriation of ICTs, while other more recent studies found that the situation is much more complex since rural areas are not necessarily less equipped than urban areas. Probably the lack of clarity and of coherence, which characterizes the results of research regarding the relationship between the mobile phone and the rural/urban environment, is a consequence of the fact that these results are not sufficiently connected to any historical moment [4]. Thus, there is the need to historicize them. In fact, if we put these studies in an historical perspective, we are able to take into account the important social phenomena and processes that intervened at a macro level in society, in the territorial division and organization of labor which changed tremendously the socio-economical structuring of the territory.

Not wrongly, at the beginning of the diffusion of the mobile phone, this device was considered to be an emblem of metropolitan life and of (post) modernity. It was, in fact, seen as providing people with a higher degree of individuality in terms of communication and social assembling [5] and [6] and [7] and [8] and [9] and [10]. Surely, at the early stages of its diffusion, the mobile telephone was mainly an urban tool [11: p. 53] and these studies read correctly the association between the big cities and the mobile phone. However, this vision, which sustained the "urban turn" studies, was based on an opposite distinction between urban and rural, with the consequence that their results were quite generic: up to which dimension did the city maintain this association with a higher diffusion of the mobile phone? On top of this open question, it was not clear whether the big cities arrived first in the appropriation of this device, just because of the higher speed of mobile phone adoption, or whether it was a problem of more structural correspondence between the mobile phone and the urban way of life with all its characteristics: more mobility, more diffusion of higher education, more complexity in the organization of the social sphere. Studies, which have pointed out that the adoption rates are first higher in cities but differences between urban and rural regions tend to shrink as telecommunication becomes more affordable [12: p. 599] and [13: p. 37], provide some clarification for this issue. Yet their contribution, although precious, is not sufficient to understand it in a structural and coherent way.

Looking at the sociological literature on the whole, it is evident that the studies on the relationship between public space and new technology have been dominated in this first stage of mobile phone diffusion by the "urban turn". In the mid-1990s, Graham and Marvin [14: p. 378] proclaimed that "what is emerging is a more totally urbanized world, where rural spaces and lifestyles are being drawn into an urban realm because of the time-space transcending capabilities of telecommunications and fast transportation networks”. The works by Manuel Castells [15: p. 440] and Aurigi [16: p. 47] can also be 
seen in the same vein. Later, the blurring of the urban-rural distinction became a much more debated issue in social studies. This shift in the perspective of mobile phone studies was necessary, given the fact that the diffusion of the mobile phone had, in the meantime, reached more and more people and the reorganization of the territory in industrialized countries had proceeded at a good pace. The open question at that time was: would the connection of the mobile phone to urban settings continue? [17].

With this new approach, it was possible to incorporate into the analysis important social and organizational issues involving the transformation of the specific missions of the different types of territories [18] and [19]. According to this debate, and to geographers' contributions, with the development of labor mechanization and automation, which decreased the labor requirements of the primary and extractive industries, many enterprises originally considered that "urban” began relocating to the countryside [20] and [21]. On the other hand, the rise of the service sector and information systems has contributed to the influx of workers from the countryside to urban areas [22: pp. 3-9]. As a consequence, many people today reside in one type of area but work in another, maybe far away. This implies that the sphere of their everyday life expands over several localities, with the consequence that people experience both these dimensions in their everyday life.

In this framework, the bi-polar distinction between "urban" and "rural" has become less useful as an indicator, when determining the location of a given place and its related lifestyles, that is, the social and cultural activities of the inhabitants that characterize the spatial identity of that place. That which remains between "urban” and "rural” can be split into smaller units (sub-urban, semi-urban, semi-rural etc.) in what is often called the urban-rural continuum [23] and [24] and [25]. Based on these observations, here we define urban-rural not as a dichotomy, but as a continuum consisting of locations with varied amounts of "urban" and "rural”. In practice, we operationalize the continuum on the basis of the number of inhabitants of spatial areas. We distinguished seven categories: cities of less than 5,000; 5,000-10,000; 10,000-30,000; 30,000-100,000; 100,000-250,000; 250,000-500,000 or more inhabitants. This operationalization was necessary for having a better comprehension of the rural/urban issue, which is particularly relevant not only for technology studies, but more in general also for a social policy perspective.

The article is structured as follows: after this introduction, in the next section we will discuss the notions of the urban-rural continuum and of the forms of communicative sociability and we will explain how we have operationalized them in our study. Then we will continue to show the respects in which the results of the study are expected to be of interest to various social actors and stakeholders. This third section is concluded by describing our two research questions and related hypotheses. In the fourth section we will illustrate the sample and the method applied. After this, we will move on to present our main results, which will be discussed in the last section where final remarks and suggestions for future research will conclude the article.

\section{The urban-rural continuum and the forms of communicative sociability}

The depopulation of rural and peripheral areas conjures up an image of social opacity, which may be compensated for by pursuing policies of social inclusion through communication technologies [26] and [27]. In addition, the social and technological problems of rural areas are heterogeneous and they vary between countries. The rural is no longer one distinctive, ideal type of community. There are multiple "ruralities" (like "urbanities"), and the way of using the mobile phone is dependent upon whichever dimension of rural one experiences. In this study we would go beyond the urban-rural dichotomy in 
order to see whether the equalization of the mobile phone is also confirmed when a more detailed measure of the urban-rural continuum is deployed.

Thus, the rural/urban adoption of the mobile phone should be seen as being dependent upon various socio-cultural factors, such as life situations, housing patterns and social relationships [28]. And in this connection, social and technology policies - both at the national and supranational level - should be regarded as instruments facilitating people's engagement in meaningful social practices [29] and [30]. This, however, necessitates a profound understanding of the relationship between ICTs and various forms of communicative sociability.

Let us, at this point, analyze our second issue: the relationship between the organization of the social sphere and the possession of a mobile phone in rural and urban settings. This second issue is connected to the fact that the mobile phone is considered a typical device of socialization, which is generally used to support (and sometimes to enhance) face-to-face forms of communicative sociability, or that which we would prefer to call body-to-body communication as this expression better highlights the richness of communication between individuals [31] and [32]. By this definition we mean the forms of sociability which take place mainly in public spaces and are made possible by communication both at their organization level and at their experiencing level. Sociability is generally defined as the tendency to affiliate with others and as a preference to be with others in contrast to remaining alone [33] and [34] and [35], but we prefer to refer to Putnam's notion of sociability, seen as the bridging and bonding capacity at a social level [36]. The term "communicative sociability” is here deployed to highlight that the various forms of sociability are intertwined with communication but they also generate communication (e.g. to keep “communication” alive we need to go with our friends to a restaurant or to the cinema etc.). In other words, we need to do things with people in order to nourish the communicative process. Communication needs to be conveyed and supported by shared activities. As communication is an action with a low output of energy, to be effective and to last over time it has to be embedded in defined, social activities, which imply a higher energy requirement. Going to the cinema or to a football match not only keep friendship alive, but in turn put in motion the communication process, since we may pass comments on the movie together with our friends or we may discuss with them the strategies employed in the football match.

Furthermore, the management of this intertwining of sociability and communication is increasingly characterized by the use of ICTs, especially the mobile phone, which has become a powerful support of mediated communication in interpersonal relations and sociability practices [37]. The other research question here is that of the role of technology with respect to sociability and communication. Does technology, in this case the mobile phone, increase, decrease or have no influence at all on the degree of development of sociability practices and in the quantitative dimensions of the communication process? This question is also at the heart of ICT research as prior research has produced contradictory results related to it. For example, while several authors found that the mobile phone is associated with the increase in sociability practices, others found that the impact of the mobile phone on sociability is rather limited compared with the impact of the Internet [38].

Prior studies indicate some interesting results regarding the relationship between the adoption of the mobile phone, the urban-rural distinction and sociability forms. For instance, regarding some specific user groups, such as children, studies have still found differences between different sized cities concerning the ownership and usage of mobile phones [39]. Our interest here is to see how the adoption of the mobile phone is connected to various forms of sociability in different geographical settings. 
Previous studies suggest, on the one hand, that activities such as going out to restaurants, pubs and bars and spending time in cafes could be powerful predictors of mobile phone use [3]. On the other hand, studies have not found a linkage between the use of the mobile phone and people's involvement in clubs and associations [40]. Furthermore, by analyzing authentic mobile call data records, some differences in mobile phone behavior have been found between urban and rural locations [41].

Despite these, many relevant research projects have been qualitative or present national data, which does not allow cross-cultural comparisons. Yet, quantitative research and statistical analysis modeling the dynamics between the spatial factors and the social organization of daily life in a cross-cultural framework is in its infancy. And it is exactly this gap which we aim to bridge with our study.

\section{Policy relevance and hypotheses}

A better understanding of these two issues - geographical differentiation and socialization in relation to the possession of a mobile phone - could be beneficial at a practical socio-political level, where, currently, local municipalities and governments have to make decisions on implementing, in their territories, telecommunication infrastructures related to the sustainable development of their communities [42]. Whereas a large part of the basic telecommunication infrastructure is built by private companies, many smaller municipalities are forced to find alternative ways to implement the latest and more expensive infrastructure (e.g. fiber optic broadband or wireless network). Market-based companies are not always willing to build expensive infrastructures for the most sparsely populated areas without subsidies, and small towns and villages often have few economic and human resources [43]. The social sphere depends in some measure on the existence, maintenance or new implementation of public infrastructures, such as museums, theatres, stadiums and many other sporting facilities, which generally in Europe are financed and managed by local municipalities with the support of some national funding, along with infrastructures such as cinemas, restaurants, bars or pubs, and dance venues, which generally depend on private initiatives. At the same time local municipalities have to deal with political guidelines dictated by the national state and the European Union. At both national and European levels, regulatory and security policies are outlined in order to guarantee citizens a balanced framework for the organization of their everyday life.

However, in this picture an appropriate knowledge of citizens' needs, desires and behavior regarding the adoption of telecommunications is often overlooked, although it is well known that the appropriation of telecommunications is related to the ways in which people organize their social life and the many forms in which they fully express their sociability. So, with this study, we intend to overcome this gap by offering a picture of how possession of the mobile phone is associated with the organization and structure of the social sphere in the five most populous and economically prosperous European countries: Italy, Germany, France, Spain and the United Kingdom (UK).

The article focuses on these five European countries, because they are all major players in defining European telecommunication policies. The electronic communication sector has had a particular significance and relevance for European integration since the early 1980s, as Preston, Cawley and Metykova argue [44]. In the European Union, telecommunications infrastructure has been considered as a facilitator, especially in the areas of trade and other economic activities, also in building closer relationships between the member states. The latest EU information society initiatives, such as i2010 [45] and Digital Agenda for Europe [46], have been attempts to create a single European space for internal markets in electronic telecommunications, to promote growth and in general to improve the 
quality of life for all EU citizens. Furthermore, the EU's information policy recognizes that ICT policies have established their role as a major driver of Europe's social, as well as economic, modernization [47: p. 3]. Having said that, exploring the spatial settings in which the mobile phone is most diffused in Europe and the ways in which the various forms of sociability are related to its possession appears to be decisively relevant at a socio-political level (as we discussed above), and also fills the gap in the related sociological literature on rural/urban and technology studies. Particular attention is paid here to finding out which are the most important variables in explaining possession of a mobile phone with respect to the social sphere and to the practices of communicative sociability in the urban-rural continuum in which people live nowadays.

Lastly, based on the contextual analysis presented above and the findings of prior studies, the following research questions and hypotheses were set.

RQ1: does the lack of differences in the possession of a mobile phone detected in studies premised on the idea of the urban-rural dichotomy remain also in the presence of a more detailed measure of the urban-rural continuum? H1: the application of a more detailed measure of the urban-rural continuum might reveal some subtle differences in the possession of a mobile phone.

RQ2: is the organization of the social sphere associated with the possession of a mobile phone in rural and urban settings? And, if yes, are all of the forms of sociability or only some of them connected? H2: sociability is significantly connected with the possession of a mobile phone, but maybe not all sociability forms are connected with the same intensity.

By answering these two research questions and testing the related hypotheses, the article is expected to contribute to mobile communication studies and more to social and public policy account on telecommunications by moving beyond the urban-rural dichotomy and showing the connection between the possession of a mobile phone and various forms of communication sociability in diverse geographical settings. The study is based on a large survey data, which makes country comparisons possible but also allows us to control a variety of socio-demographic variables. Furthermore, it may help telecom sector and public authorities to better understand the role of daily social activities in the adoption and use of ICTs.

\section{Sample and method}

The article is based on a survey that was carried out in the five most populous and industrialized European countries: Italy, France, UK, Germany and Spain $(\mathrm{N}=7,255)$ in 2009. The sample is representative of the populations of these countries and is structured as follows: Italy $(\mathrm{N}=1,398)$, France $(\mathrm{N}=1,424)$, Germany $(\mathrm{N}=1,919)$, $\mathrm{UK}(\mathrm{N}=1,411)$ and Spain $(\mathrm{N}=1,103)$. The study partially replicates research carried out in 1996 in the same countries [48]. ${ }^{1}$ Both studies were funded by Telecom Italia. The structured survey included questions on the diffusion of the mobile phone and on socio-demographic variables, as well as on the level and frequency of forms of communicative sociability, defined (through a pre-test administered to 100 respondents) as reported in the Appendix.

The data was collected by means of a fixed telephone survey (the field research is reported in the Appendix). In this study we used weighted data in order to correct some distortions (related to age,

\footnotetext{
${ }^{1}$ To simplify our language we will use the term Europe and Europeans to indicate these five countries and their populations.
} 
education, ownership of a computer and access to the Internet) which affected the correct representation of the various quotas of the sample.

The socio-demographic variables included in the analyses of this article were gender, age, education, family typology, the size of the city of residence, and country. Among the respondents, 3,551 were male (48.9\%) and 3,704 were female (51.1\%). The respondents' ages were measured in years and afterwards categorized into five groups (14-17, 18-24, 25-44, 45-64 and 65 years and over). The family typology was divided into singletons, couples without children, couples with children, singleparent families and mixed families (all other types of families). Education level was divided into the following categories: low (primary and secondary school diploma), middle (high school diploma) and high (College/University degree or higher). Finally, as we anticipated, seven categories were distinguished with respect to city size to indicate the urban-rural continuum (cities of less than 5,000; 5,000-10,000; 10,000-30,000; 30,000-100,000; 100,000-250,000; 250,000-500,000; 500,000 or more inhabitants). or more inhabitants After careful analysis, some other socio-demographic background variables were excluded from the study. For example, such variables as income and professional status showed no explanatory capacity when included in a regression analysis and a measure of the current occupational status of the respondent negatively affected a statistical test for goodness-of -fit (Hosmer and Lemeshow Test) and was therefore omitted from the analysis.

The article deploys both bivariate analytical tools, such as chi-square tests and standardized residuals [49: pp.46-48] and [50: pp.698-700] ${ }^{2}$, and logistic regression analysis with an entered model. The Hosmer and Lemeshow test was used to indicate the goodness-of-fit of logistic regression modeling. To identify the overall proportion of the variance explained by our model, we referred to the Nagelkerke-statistics [51: pp. 459-61]. A dichotomous question about the possession of mobile phones was used as a dependent variable in the regression analysis, and a set of continuous, discrete and dichotomous variables measuring demographic and spatial factors as well as various forms of sociability were entered as independent variables.

\section{Results}

Let us start with the description of the differences we found in the possession of mobile phones in relation to the various background variables, geographical factors and the main forms of communicative sociability. Our aim here was to find out whether there is any difference in the ownership of mobile phones in relation to the various background variables, geographical factors and the organization of the relational sphere in everyday life. Table 1 reports the first set of data related to the relationship between the possession of a mobile phone and the structural and geographical variables, while Table 2 illustrates the relationship between the ownership of mobile phones and the various forms of communicative sociability. Table 3 reports the first set of data related to the relationship between the possession of a mobile phone and the structural and geographical variables, and Table 4 reports the results of the regression analysis.

\section{Insert Table 1 here}

\footnotetext{
2 The analysis of standardized residuals is based on the identification of the cells of a contingency table which are responsible for a significant overall chi-square. Values outside of +/- 1.96 are interpreted as statistically significant. However, to simplify the analysis we will read only the positive residuals.
} 
Table 1 gives an answer to our first research question and supports the first hypothesis that the application of a detailed measure of the urban-rural continuum reveals some differences (although minor) in the rates of mobile phone possession. Small towns from 10,000 to 30,000 and smaller cities of 30,000-100,000 differ statistically from the rest by having a smaller proportion of inhabitants not having a mobile phone. This is a weak signal of differences which do not exist between the most rural and most urban areas, but which emerge from the middle of the urban-rural continuum.

Table 1 also shows that, regarding the demographic background variables, mobile phone ownership rates are higher among men than women in the five selected countries. Table 1 also indicates that possession of mobile phones is more widespread among the younger age groups than among the older ones. The ownership rate continues to be at a remarkably low level in the group of respondents aged 65 years and over when compared to all the others. Furthermore, the analysis shows that owning a mobile phone is more typical for families, especially for couples with children, than for single persons. In this, children seem to be the true driver of technological updating in their families. Also the high level of education is still connected to possession of mobile phones. We were also able to register statistically significant differences between the five countries. Italy is the country with the highest level of mobile phone ownership, followed by the UK and Spain, while France and Germany share last place.

\section{Insert Table 2 here.}

Before illustrating the results on sociability and diffusion of the mobile phone in the urban-rural continuum, we considered it essential to describe in Table 2 how the structure of the social sphere is associated with city size (see the original formulation of these questions in the Appendix). The most intimate forms of sociability such as visits to friends and relatives are practiced more in small villages and towns, while cultural and sporting activities, as well as activities related to social participation, are performed to a lesser extent. Cultural sociability is more developed in big cities. Going to restaurants is the most common practice in large cities of 500,000 and more inhabitants, while going out with friends for example to do window shopping is a much more common practice in locations of more than 10,000 inhabitants. Taking part in sporting activities takes place more extensively in large cities than in small towns and villages. Finally, participation in various types of civil society activities is an activity of big cities.

Table 3, which concerns the organization of the social sphere, illustrates the answer to our second research question.

\section{Insert Table 3 here.}

Our data provides support for Hypothesis 2 as not only social participation in clubs and the like but also some other forms of sociability are not clearly associated with the possession of a mobile phone. Table 3 shows that the rate of mobile phone ownership is, in general, significantly higher among those who practice the main forms of communicative sociability. But if we look at them in particular, the picture shows several differences: those who go to restaurants, bars and such like, and who spend time with their friends at home or outside, register higher rates of mobile phone ownership. Also, taking part in sporting and cultural activities is linked with the possession of mobile phones, although to a lesser degree. In contrast, meeting relatives is significantly associated with the variable in question but with 
less intensity. As hypothesized, the only clear exception is participation in civil society activities, such as clubs, trade unions or politics, which is not associated with the possession of a mobile phone. A similar finding was reported by Fortunati and Manganelli [52] and Campbell and Kwak [40: p. 444], but in these cases the association was relative to the use of the mobile phone. Campbell and Kwak (ibid.) in particular show that mobile phone voice calling and text messaging are not related to a higher degree of involvement in clubs and activity groups, such as a knitting group, a bridge club or a service club, such as the Lions, in the United States. Some other studies instead suggest that mobile phone use may be associated with less involvement in associations and in the larger society, but on the contrary, it may make people’s participation in their personal networks easier [53] and [54: p. 383].

These bivariate analyses show interesting results, but the most important variables in explaining the possession of mobile phones as regards the social sphere, that is the practices of communicative sociability in the spatial continuum in which people live nowadays, once all the independent variables have been controlled inside the same model, remain to be understood. To deal with this issue, we executed a logistic regression analysis, which is presented in Table 4. The model consists of three types of variables: socio-demographic variables, spatial factors and different forms of sociability. The first variables, gender (dummy variable), age (five categories), education (three categories) and family type (five categories), are needed in order to control the relationship between mobile phone ownership, spatial factors (city size and country) and forms of sociability. The second group of variables includes two spatial indicators, namely the size of the city of residence and the country. The third set of variables consists of indicators of the social sphere in the form of the main practices of communicative sociability. Five questions considering different practices of social activities and two questions about visiting and inviting friends and relatives were included.

\section{Insert Table 4 here.}

The regression model presented in Table 4 passed the Hosmer and Lemeshow test (sig=.174). It managed to predict correctly $98 \%$ of those who own a mobile phone and according to the Nagelkerkestatistics the model explains $23 \%$ of the total variance in the possession of mobile phones. On the contrary, the capacity of this model to classify correctly non-owners was at a considerably lower level (16\%). This indicates that non-ownership of a mobile phone is not clearly related to spatial factors, such as the size of the city of residence, or the organization of social life used in the model.

The results of the logistic regression analysis shed a more intense light on our research questions and related hypotheses. They confirm Hypothesis 1 suggesting that there are minor differences in the possession of a mobile phone between urban and rural areas. The analysis confirms that there is no longer duality between rural towns and urban territories and this is in line with the literature of the second wave of studies on mobile phone diffusion. People living in the countryside, small villages and towns are as likely as the people of the big cities to possess a mobile phone. Some similar findings have also been reported by Taipale [3] and [11] with respect to Finland. No significant differences were registered between respondents living in the big cities and smaller towns. However, the odd ratio for the cities of 100,000-250,000 inhabitants is statistically significantly smaller than that of the reference category of less than 5,000 inhabitants. Thus, we can assume that in small cities, which represent the middle range of the urban-rural continuum, the possession of a mobile phone is less necessary with regard to its inhabitants’ ways of life than in other places. 
On the other hand, our findings do not provide full support for Hypothesis 2. The analysis shows that those who own a mobile phone practice the majority of forms of sociability more typically than nonowners. Among the various forms of sociability, mobile phone owners state more typically that they go out to restaurants, pubs or bars, or go dancing. This is an activity that is coordinated with friends in advance or en route. Generally, it does not seem that people go to these public places hoping to meet somebody that they do not know, but to stay together with people that they already know. Also, cultural activities, such as going to the cinema, theatre, opera, museums, libraries or exhibitions, as well as inviting friends and relatives to one's own home or going to visit them, are more common activities among those who have a mobile phone. Sporting activities are, to some extent, related to the possession of this device as well. Lastly, the analysis also shows no statistically significant relation with other social activities, such as going out with friends for a walk, going shopping or watching sporting events. Regression analysis also shows that mobile phone ownership could be connected to less involvement in civil society activities, such as social clubs and trade, religious, union and political activities, when the impact of various variables is controlled at the same time.

As regards gender differences, the regression analysis confirms that male respondents typically possess mobile phones more often than females. Regarding age, this model also confirms that younger respondents typically have mobile phones more often than older people. To be more specific, compared to the reference group of 14-17 year-olds, respondents of the 18-24 and 25-44 year age groups are equally likely to possess a mobile phone, whereas people of 45 years or older typically possess fewer mobile phones. The regression analysis also brings out that the higher the level of education, the more the respondent is likely to have a mobile phone.

With respect to the typology of the family, it emerged that when compared with singletons as a reference group and once all the other demographic variables were controlled, respondents belonging to couples without children are most likely to own mobile phones than those living in families made up of couples with children. On the contrary, respondents living in single-parent or mixed families do not show significant differences compared to the reference group of single persons. As regards the country variable, it emerges, unsurprisingly, that the country which has more mobile phones is Italy, followed by the UK and Spain, while Germany and France have significantly fewer mobile phones.

\section{Discussion and final remarks}

This article confirms that there is no longer a dichotomy between rural towns and urban territories when it comes to the possession of mobile phones. The small differences among the different city sizes mean that diffusion of the mobile phone occurs irrespective of the cultural and social implications of the proximal space. Maybe because the true space of the mobile phone is the human body (the hand) and clothing (i.e. pocket, bag). The mobile phone is portable and accompanies individuals in their mobility as well in their being in sedentary places (home, work, school, etc.). Moreover, there can be another element: big cities are able to offer more choices, but in compensation the difficulties connected to mobility (traffic, long distances, lack of safety, etc.) tend to discourage citizens from practicing sociability. On the contrary, small villages or middle-sized towns offer less choices (maybe one cinema and perhaps one theatre) but in compensation mobility is much easier (no traffic, short distances and more safety). In the end, the practice of all these forms of communicative sociability does not present significant differences. Probably the diffusion of mobile phones concurs with other ICTs, especially the Internet, in resizing the differences in everyday life between the rural and the urban. Whether this represents an increase in modernization and industrialization of the countryside or a loss 
of competitiveness at a technological level on the part of the big cities remains an open question which requires further research.

Having said that, the reason the rate of possession of the mobile phone is smaller in the middle cities of 100,000-250,000 inhabitants remains to be discussed. These middle cities are also those where generally the quality of life, which is measured through a broad range of indicators, is higher. It seems that a moderate spatial extension of the city area, moderate mobility (with a relatively short commuting time), and a certain economical well-being, makes the mobile phone less useful. In fact, it seems that the city of 100,000 to 250,000 inhabitants is a kind of golden section of the social sphere, built more upon body-to-body relationships. However, this is a result which deserves more discussion and research.

Possession of a mobile phone is still evolving differently in the various countries investigated and shows once more that there is not an optimal rate of diffusion of communication and information technologies, but that every country metabolizes the single technology according to its communicative and social needs, which are not standard across Europe [55]. Thus, further research is required to study country differences in the ways sociability practices influence the adoption and use of new communication technologies. In addition to European approaches, more studies with focus on countries representing different continents should be conducted. In fact, this study indicates that country differences are more important predictors for the possession of mobile phones than the differences in the size of the city of residence.

Country differences are probably related to the fact that the diffusion of the mobile phone is influenced by the various cultures, which include a certain level of income, specific social personality, peculiar communicative practices, particular organization of public and private institutions such as family, educational and media systems, and so on, specific collective behaviors, certain climate conditions and many other factors. Taking for granted the fundamental, cultural difference of being Italian rather than British, all the other differences introduced by the urban-rural continuum or by the different size of the city in which one lives, do not have an impact on the possession of a mobile phone. If the mobile phone, for example, serves to overcome local distances, whether this distance is in a metropolis or in a rural town, does not make a big difference.

Men are still more likely than women to own a mobile phone. While among the younger generations there are no gender differences in this respect, the gender divide is far from being reduced among women of a certain age. Furthermore, young people still show more inclination towards this tool than the elderly, although the elderly are rapidly catching up. The mobile phone as an artifact still has a long way to go in order to be designed appropriately for the elderly.

People living as couples without children tend to own mobile phones more than other groups. This fact can make us think that the necessity and the pleasure of buying a mobile come more from the needs of the couple rather than the need by the parents to coordinate with children (see also [56]). Probably couples without children concentrate more on their relationship and on communication between them. And this might push them in more and more cases to resort to the mobile phone. This result should encourage the telecommunications sector to develop mobile phone models, applications and services that could be used to support intra-family communications. And further, public sector actors should also recognize the underutilization of the capacity of mobile phones when developing new strategies aiming to strengthen family cohesion.However, it is evident that more research is required to ascertain 
the purposes for which mobile phones are used in different types of families and who is communicating with whom.

This article also shows that the possession of a mobile phone is significantly related to the majority of forms of sociability. The forms of sociability such as going out to restaurants, pubs or bars, or going dancing, are most common among mobile phone owners as these activities clearly need to by coordinated with friends in advance or en route. Also, cultural activities, such as going to the cinema, theatre, opera, museums, libraries or exhibitions, as well as inviting friends and relatives to one's own home or going to visit them, are more experienced by those who have a mobile phone. Sporting activities are, to some extent, related to the possession of this device as well. Instead, no statistically significant relation with other social activities, such as going out with friends for a walk, going shopping, watching sporting events or being involved in civil society, emerged. Probably the possibility to coordinate with others even when on the move makes the difference in the capacity of sociability building, because this gives flexibility and facilitates taking advantage of breaks and slack moments. The possession of a mobile phone with the perpetual contact gives us the opportunity to optimize all our initiatives and organizational possibilities in every moment as well as to give us a sense of safety. This in the end results in an increase in the amount of social activities one performs. On the contrary, the mobile phone is perhaps not the most useful tool for supporting some specific social activities, such as going out with friends for a walk, going shopping, watching sporting events or doing political, union or voluntary activity. Regarding the first two, this is maybe because they imply to a simple form of socialization with another person. Political, union and voluntary activities, in turn, may be better supported by other media such the Internet. Lastly, our findings suggest that people seem to go to public places not hoping to create new relationships but to stay together with people they know already. Regarding studies which show that the use of ICTs has a decreasing effect on body-to-body communication [57], this study instead shows the opposite along with other studies such as that carried out by Campbell and Kwak [40]. The use of the mobile phone is one of the factors which explain the permanence of forms of communicative sociability. This means that the mobile phone is useful in supporting the organization of the social sphere [58].

Lastly, the article demonstrates to policy makers, local authorities and private sector actors that social infrastructures, such as cinemas, theatres, restaurants and museums are also vital to the life of small sized communities. Also, in rural areas citizens are techno-citizens or e-actors [58] and this represents a challenge for administrators but also an opportunity to guarantee them a better life. Based on our study, social activities especially, such as spending time in restaurants and the like, going to the cinema and taking part in sporting activities, are related to a higher adoption of new ICTs, such as the mobile phone. This makes us suggest that this aspect too should be taken into account in public policies while thinking about ways to keep remoter regions vital. Private companies should also recognize that it is these particular social activities that have lots of potential when it comes to developing new ancillary mobile service and applications.

\subsection{Limitations and suggestion for future research}

As we have already noted, the fact that the regression model is not able to explain the non-possession of a mobile phone suggests that the reasons for not buying this device are not connected to the specific variables considered in this analysis. Maybe psychological and economical reasons are influential here. In fact, from the answers to another question in this questionnaire, we know that the reasons for not 
buying a mobile phone reported by the respondents who do not have this device $(\mathrm{N}=1,017)$ are: I do not need it (70.6\%) and I do not like it (11.6\%). But what this answer "I do not need it" means is not at all clear and remains to be investigated, even if only to ascertain that these non-owners are most typically older people (65+ year-olds).

Second, the reasons that the middle sized cities are less equipped for mobile phones need to be investigated further. We advanced some explanations but a systematic study is necessary to better understand this point. This study also hints that focusing only on the possession of this device instead of also exploring different ways of using it, is very limitative. Future research also needs to explore the consumption of the mobile phone as well as the modalities and the contexts of its practices of use, in order to better understand how, through the use of the mobile phone, people manage communicative sociability and the organization of the social sphere in general, in rural/urban environments.

\subsection{Role of the funding source}

Telecom Italia financed the survey. The questionnaire was a version revised by the first author and by Anna Maria Manganelli of the one used in a previous survey in 1996. The first survey was promoted by the first author and designed by an international group of scholars: in addition to the first author, Gérard Claisse, Leslie Haddon, Ulrich Lange and Josep Burcet, were involved. They worked in collaboration with Marina Chiaro of Telecom Italia. In its replication in 2009, the re-modeling of the questionnaire was made by the first author and Anna Maria Manganelli. The research institutes which carried out the survey were, in 1996, Infratest Burke and, in 2009, IPSOS. Telecom Italia funded the two surveys. Telecom Italia kept the data of the survey for six months and then gave them to the first author.

\section{References}

[1] W. Chen and B. Wellman Charting digital divides. Comparing socio-economic, gender, life-stage and rural-urban Internet access and use five countries. In: W. H. Dutton, B. Kahin, R O'Callaghan and A. W. Wyckoff, Editors, Transforming enterprise: the economic and social implications of information, The MIT Press, Cambridge, MA: (2005).

[2] R. Gilligan, Questioning the 'rural' adoption and use of mobile ICTs. In: L. Haddon, E. Mante, B. Sapio, K.-H. Kommonen, L. Fortunati and A. Kant, Editors, Everyday innovators: Researching the role of users in shaping ICTs, Springer, Dordrecht (2005).

[3] S. Taipale, Does location matter? A comparative study on mobile phone use among young people in Finland, The Journal of New Media and Culture 6 (1) (2009a). Retrieved 16 June, 2010 http://www.ibiblio.org/nmediac/summer2009/MobileLocation.html.

[4] J. Katz, Editor, The handbook of mobile communication studies, The MIT Press, Cambridge, MA (2008).

[5] T. Kopomaa, City in your pocket. Birth of the mobile information society. Gaudeamus, Helsinki (2000).

[6] A. M. Townsend, Life in the real-time city: Mobile telephones and urban metabolism, Journal of Urban Technology 7 (2000), pp. 85-104.

[7] P. Mäenpää, Mobile communication as a way of urban life. In: J. Gronow and A. Warde, Editors, Ordinary consumption, Routledge, London (2001). 
[8] J. R. Höflich, A certain sense of place: Mobile communication and local orientation. In: K. Nyíri, Editor, A sense of place: The global and the local in mobile communication, Passagen Verlag, Vienna (2005).

[9] R. M. Rettie, Presence and embodiment in mobile phone communication, PsychNology Journal 3 (2005), pp. 16-34.

[10] S. Williams and L. Williams, Space invaders: the negotiation of teenage boundaries through the mobile phone, The Sociological Review 53 (2005), pp. 314-331.

[11] S. Taipale, Transformative technologies, spatial changes. Essays on mobile phones and the Internet. (Jyväskylä Studies in Education, Psychology and Social Research No. 362), University of Jyväskylä, Jyväskylä, Finland (2009b).

[12] R. E. Rice and J. E. Katz, Comparing internet and mobile phone usage: Digital divides of usage, adoption and dropouts, Telecommunications Policy, 27 (2003), pp. 597-623.

[13] V. Andonova, Mobile phones, the Internet and the institutional environment, Telecommunications Policy 30 (2006), pp. 29-45.

[14] S. Graham and S. Marvin Telecommunication and the city: Electronic spaces, urban places, Routledge, New York, NY (1996).

[15] M. Castells, The Information age: Economy, society and culture. Volume I. The rise of network society (2nd ed), Blackwell, Oxford (2000).

[16] A. Aurigi, Making the digital city. The early shaping of urban internet space, Ashgate, London (2004).

[17] V. Oksman and J. Turtiainen, Meanings of mobile communication in everyday life among teenagers in Finland. Mobile communication as a social stage, New Media \& Society 6 (3) (2004), pp. 319-39.

[18] D. Massey, Politics and space-time, New Left Review 196 (1992), pp.65-84.

[19] D. Massey, For Space, Sage, London (2005).

[20] R. Dewey, The rural-urban continuum: Real but relatively unimportant, American Journal of Sociology 66 (1960), pp.60-66.

[21] R. Pryor, Defining the rural-urban fringe, Social Forces 47 (1968), pp. 202-215.

[22] A. Champion and H. Graeme, New forms of urbanization: Beyond the urban-rural dichotomy, Ashgate, London (2004).

[23] R. E. Pahl, The rural-urban continuum, Sociologia Ruralis 6 (1966), pp. 299-327.

[24] D. B. Hindman, The rural-urban digital divide, Journalism \& Mass Communication Quarterly 77 (3) (2000), pp.549-560.

[25] M. J. Stern and B. Wellman Rural and urban differences in the Internet society - real and relatively important, American Behavioral Scientist 53 (2010), pp.1251-1256.

[26] A. Calabrese and J. C. Burgelman, Editors, Communication, citizenship and social policy, Rowman \& Littlefield, Lanham, MD (1999).

[27] T. Fitzpatrick, Introduction: New Technologies and Social Policy, Critical Social Policy 23 (2003), pp.131-138.

[28] S. Taipale, The mobile phone: Is it an urban phenomenon? In: R. Pertierra, Editor, The social construction and usage of communication technologies: Asian and European experiences, The University of the Philippines Press, Diliman, Quezon City (2007).

[29] J. R. Höflich, Part of two frames. Mobile communication and the situational arrangement of communicative behavior. In: K. Nyiri, Editor, Mobile democracy: Essays on society, self, and politics, Passagen Verlag, Vienna (2003). 
[30] M. Warschauer, Technology and social inclusion: Rethinking the digital divide, The MIT Press, Cambridge, MA (2004).

[31] L. Fortunati, Is body-to-body communication still the prototype?, The Information Society 21 (2005), pp. 53-56.

[32] R. Ling and P.E. Pedersen, Mobile communications. Re-negotiation of the social sphere, Springer, London (2005).

[33] J. M. Cheek and A.H. Buss, Shyness and Sociability, Journal of Personality and Social Psychology 41 (2) (1981), pp. 330-339.

[34] S. Kitamura, FtF and mobile email personal networks and loneliness: Focusing on the interaction effects of sociability and personal networks, Journal of Socio-Informatics 1 (1) (2008), pp. 7186.

[35] R. Wei, Motivations for using the mobile phone for mass communications and entertainment, Telematics \& Informatics 25 (1) (2008), pp. 36-46.

[36] R.D. Putman, Bowling alone. The collapse and revival of American community, Simon \& Schuster, New York (2000).

[37] L. Fortunati and A.M. Manganelli, Young people and the mobile telephone, Revista De Estudios De Juventud 57 (2) (2002a), pp. 59-78.

[38] B. Wellman and B. Hogan, Connected lives. The project. In: P. Purcell, Editor, Networked Neighbourhoods, Springer, London (2006).

[39] G. Mezei, M. Benyi and A. Muller, Mobile phone ownership and use among school children in three Hungarian cities, Bioelectromagnetics 28 (2007), pp. 309-315.

[40] S. W. Campbell and N. Kwak, Mobile communication and social capital. An analysis of geographically differentiated usage patterns, New Media \& Society 12 (2010), pp. 435-451.

[41] N. Eagle, Y-A de Montjoye and L.M.A. Bettencourt, Community computing: Comparisons between rural and urban societies using mobile phone data, International Conference on Computational Science and Engineering (2009).

[42 ] J. Vincent and L. Harris, Effective use of mobile communications in e-government. How do we reach the tipping point?, Information. Communication \& Society 11 (2008), pp. 395-413.

[43] C. Szabó, K.Farkas and Z. Horváth, Motivations, design and business models of wireless community networks, Mobile Networks and Applications 13 (2008), pp.147-159.

[44] P. Preston, A. Cawley and M. Metykova, Broadband and rural areas in the EU. From technology to applications and use, Telecommunications Policy 31 (2007), pp. 289-400.

[45] COM, i2010 - A European information society for growth and employment. Retrieved June 14, 2010. http://eur-lex.europa.eu/LexUriServ/LexUriServ.do?uri=COM:2005:0229:FIN:EN:PDF. (2005).

[46] COM, A Digital Agenda for Europe. Retrieved March 28, 2011, http://eurlex.europa.eu/LexUriServ/LexUriServ.do?uri=COM:2010:0245:FIN:EN:PDF (2010).

[47] COM, Europe's digital competitiveness report. Main achievements of the i2010 strategy 20052009. Retrieved June 14, 2010, http://ec.europa.eu/information_society/eeurope/i2010/docs/annual_report/2009/com_2009_390 _en.pdf. (2009).

[48] L. Fortunati, Editor, Telecomunicando in Europa [Telecommunications in Europe], Angeli, Milano (1998).

[49] B. E. Everett, The analysis of contingency tables (2nd ed), FL: Chapman \& Hall/CRR, Boca Raton (1992).

[50] A. Field, Discovering statistics using SPSS (3rd ed), Sage, London (2009). 
[51] B. Tabachnick and L. Fidell, Using multivariate statistics (5th ed), Pearson, Boston, MA (2007).

[52] L. Fortunati and A.M. Manganelli, Mobile communication and social participation. In: J. E. Katz, Editor, Mobile communication and social policy, NJ: Transactions, New Brunswick (2011).

[53] R. Ling, B. Yttri, B. Anderson and D. DiDuca, Mobile communication. and social capital in Europe. In: K. Nyíri, Editor, Mobile democracy: Essays of society, self and politics, Passagen Verlag, Vienna (2003).

[54] S. Sugiyama and J. E. Katz, Social conduct, social capital, and the mobile phone in the U.S. and Japan: A preliminary exploration via student survey. In: K. Nyíri, Editor, Mobile democracy: Essays of society, self and politics, Passagen Verlag, Vienna (2003).

[55] L. Fortunati and A.M. Manganelli, A review on the literature on gender and ICTs in Italy. In: K. H. Sørensen and J. Stewart, Editors, Digital divides and inclusion measures. A review of literature and statistical trends on gender and ICT, NTNU, Trondheim/Edinburgh (2002b).

[56] A. Lasen, Mobile culture and subjectivities: An example of shared agency between people and technology. In: L. Fortunati, J. Vincent, J. Gebhardt, A. Petrovcic, and O. Vershinskaya, Editors, Interacting with broadband society, Peter Lang, Berlin (2010).

[57] K. J. Gergen, Mobile communication and the transformation of democratic process. In: J. Katz, Editor, Handbook of mobile communication studies. The MIT Press, Cambridge, MA (2008).

[58] P. Glotz, S. Bertschi and C. Locke, The introduction: mobile phones and the social order, Knowledge, Technology, and Policy 19 (1) (2006), pp. 3-7.

[59] L. Fortunati, J. Vincent, A. Gebhardt, A. Petrovcic and O. Vershinskaya, Editors, Interacting with broadband society, Peter Lang, Berlin (2010). 
Appendix

This survey was based only on fixed telephone numbers for organizational reasons; not least the lack of a directory of mobile phone numbers in several countries. The problem is well known at a statistical level, even if it is not easy to find a solution. Of course, in the fixed telephone survey, mobile-only households are under-represented. However, we recall that the survey data were subsequently weighted taking this issue into account.

1) The questions we posed regarding the behavior related to the relational sphere at a social level are as follows:

Do you ever invite into your home or go to visit:

- Friends?

- Relatives?

For each "yes": How often?

- $\quad$ Several times a week

- Once a week

- Once/twice a month

- $\quad$ Less often

In your leisure time, how often do you go out:

1) To the cinema, theatre, opera, museums, libraries or exhibitions?

2) To restaurants, pubs and bars, or to go dancing?

3) To go out with friends for a walk, to go shopping or to watch sporting events?

4) To take part in sporting activities?

5) To take part in clubs, or religious, trade union or political activities?

Frequency:

- $\quad$ Several times a week

- Once a week

- Once/twice a month

- Less often

- No/Never

2) This survey is based on a sample per quota which is representative of the populations of the 5 countries aged from 14 to 70 years. The variables that have been considered to control the sample are:

- $\quad$ gender crossed by age (10 cells of sampling: 2 for 5 age ranges)

- $\quad$ number of family members (three levels)

- geographical area (depending on each country)

The source for the construction of the quotas is Eurostat, in particular its data from 2007 for age and 2005 for the number of family members.

The field report of the survey is summarized below:

Total contacts

Italy France UK

Germany

Spain

complete interviews

$1,399 \quad 1,424$

(2.8\%) (14.2\%)

Refusals at the

beginning

39,290 6,863

(77.9\%) (68.4\%)
1,412

(14.5\%)

6,893

$(70.7 \%)$
1,920

(19.3\%)

1,104

(10.9\%)
6,775

(67.9\%)
7,489

(74.1\%) 


\begin{tabular}{|c|c|c|c|c|c|}
\hline Interrupted interviews & $\begin{array}{l}864 \\
(1.7 \%)\end{array}$ & $\begin{array}{l}252 \\
(2.5 \%)\end{array}$ & $\begin{array}{l}281 \\
(2.9 \%)\end{array}$ & $\begin{array}{l}265 \\
(2.7 \%)\end{array}$ & $\begin{array}{l}230 \\
(2.3 \%)\end{array}$ \\
\hline $\begin{array}{l}\text { Respondents out of } \\
\text { target or quota }\end{array}$ & $\begin{array}{l}7,157 \\
(14.2 \%)\end{array}$ & $\begin{array}{l}907 \\
(9.0 \%)\end{array}$ & $\begin{array}{l}845 \\
(8.7 \%)\end{array}$ & $\begin{array}{l}820 \\
(8.2 \%)\end{array}$ & $\begin{array}{l}1,038 \\
(10.3 \%)\end{array}$ \\
\hline Wrong numbers & $\begin{array}{l}721 \\
(1.4 \%)\end{array}$ & $\begin{array}{l}479 \\
(4.8 \%)\end{array}$ & $\begin{array}{l}247 \\
(2.5 \%)\end{array}$ & $\begin{array}{l}128 \\
(1.3 \%)\end{array}$ & $\begin{array}{l}88 \\
(0.9 \%)\end{array}$ \\
\hline $\begin{array}{l}\text { Not to be found } \\
\text { appointments }\end{array}$ & $\begin{array}{l}1,059 \\
(2.1 \%)\end{array}$ & $\begin{array}{l}108 \\
(1.1 \%)\end{array}$ & $\begin{array}{l}77 \\
(0.8 \%)\end{array}$ & $\begin{array}{l}65 \\
(0.7 \%)\end{array}$ & $\begin{array}{l}152 \\
(1.5 \%)\end{array}$ \\
\hline $\begin{array}{l}\text { The average duration } \\
\text { of the interview was }\end{array}$ & $25^{\prime}$ & $24^{\prime}$ & $24^{\prime}$ & $23^{\prime}$ & 26 \\
\hline
\end{tabular}


Table 1. Background variables by ownership of the mobile phone Mobile Phone Ownership

\begin{tabular}{|c|c|c|c|c|c|}
\hline \multirow{2}{*}{\multicolumn{6}{|c|}{ Chi-squar }} \\
\hline & & & & & \multirow{3}{*}{$59.2 * * *$} \\
\hline- & Male & $13.9 *$ & $86.1^{*}$ & 3551 & \\
\hline & Female & $20.8 *$ & $79.2 *$ & 3704 & \\
\hline \multicolumn{6}{|c|}{ Age } \\
\hline & $14-17$ & $10.5^{*}$ & 89.5 & 1119 & \multirow[t]{5}{*}{$674.8 * * *$} \\
\hline & $18-24$ & $4.4^{*}$ & $95.6^{*}$ & 1104 & \\
\hline - & $24-44$ & $7.9 *$ & $92.1^{*}$ & 1271 & \\
\hline - & $44-64$ & $19.6^{*}$ & 80.4 & 1228 & \\
\hline - & $65+$ & $37.0 *$ & $63.0 *$ & 988 & \\
\hline
\end{tabular}

Family type
- Single

- Couple, no children

- Couple with children

- One parent with children

- Blended families
$25.4^{*}$

18.9

$11.1^{*}$

14.4

17.4

$25.6^{*}$

$14.3 *$

12.6*

- Medium

- High

City size

- Up to 5000

- $5000-10000$

- $\quad 10000-30000$

- $30000-100000$

- $100000-250000$

- $250000-500000$

- 500000 or more
16.3

14.2

$13.9 *$

$14.5^{*}$

19.6

14.6

16.1
74.6*

81.1

88.9*

85.6

82.6
1375

1714

2571

411

671
$157.8^{* * *}$

$\begin{array}{ll}74.4^{*} & 2083 \\ 85.7 & 3215 \\ 87.4^{*} & 1798\end{array}$

$149.0 * * *$

1798

(sig)

Country

- Italy

- France

- Germany

- United Kingdom

- Spain

$7.1^{*}$
$23.4^{*}$
$23.4^{*}$
$12.2^{*}$
19.1

83.7

85.8

86.1

85.5

80.4

85.4

83.9
657

557

813

1017

812

637

1427

Sig: $*=\mathrm{p}<.05, * *=\mathrm{p}<.01, * * *=\mathrm{p}<.001$.

\footnotetext{
* Standardized residuals higher than $\mathbf{2 . 0}$ and lower than -2.0 are statistically significant
} 
Table 2. Forms of communicative mobility by city size

Sig: $*=\mathrm{p}<.05, * *=\mathrm{p}<.01, * * *=\mathrm{p}<.001$

\begin{tabular}{|c|c|c|c|c|c|c|c|c|}
\hline & \multicolumn{8}{|c|}{ City size } \\
\hline & $\begin{array}{l}\text { Up to } \\
5000\end{array}$ & $\begin{array}{l}5.000- \\
10.000\end{array}$ & $\begin{array}{l}10.000- \\
30.000\end{array}$ & $\begin{array}{l}30.000- \\
100.000\end{array}$ & $\begin{array}{l}100.000- \\
250.000\end{array}$ & $\begin{array}{l}250.000- \\
500.000\end{array}$ & $\begin{array}{l}500.000 \\
+\quad\end{array}$ & $\begin{array}{l}\text { Chi-square } \\
\text { (sig) }\end{array}$ \\
\hline \multicolumn{9}{|l|}{ Do you ever visit or invite at home: } \\
\hline - Friends & 90.3 & 87.8 & 89.3 & 86.4 & 83.5 & 84.0 & 79.9 & $113.1 * * *$ \\
\hline - Relatives & 90.0 & 88.3 & 86.0 & 83.7 & 80.3 & 82.3 & 84.0 & $40.3^{*}$ \\
\hline \multicolumn{9}{|l|}{ In your leisure time, do you: } \\
\hline - To the cinema etc.? & $69.5^{*}$ & 73.3 & 79.3 & 77.5 & 83.6 & 83.4 & $84.4^{*}$ & $137.7 * * *$ \\
\hline - To restaurants, etc.? & 81.1 & 83.5 & 86.7 & 84.9 & 84.1 & 84.0 & $87.5^{*}$ & $159.8 * * *$ \\
\hline - To go out with friends etc.? & 80.8 & 82.2 & 85.5 & 86.0 & 85.3 & 84.1 & 85.6 & $105.9 * * *$ \\
\hline \multirow[t]{2}{*}{ - To take part in sporting activities? } & 54.2 & 54.8 & 56.3 & 59.3 & $61.6^{*}$ & 56.4 & $63.4^{*}$ & $171.8^{* * *}$ \\
\hline & $39.6^{*}$ & 42.8 & 44.3 & 46.7 & $53.3^{*}$ & 47.3 & $57.5^{*}$ & $232.2^{* * *}$ \\
\hline - To take part in clubs etc? & & & & & & & & \\
\hline$N$ & 657 & 557 & 813 & 1017 & 812 & 637 & 1427 & \\
\hline
\end{tabular}

* Standardized residuals higher than $\mathbf{2 . 0}$ and lower than $\mathbf{- 2 . 0}$ are statistically significant 
Table 3. Forms of communicative sociability by ownership of the mobile phone

\section{Mobile Phone Ownership}

\begin{tabular}{|c|c|c|c|c|c|}
\hline & No & Yes & $\mathrm{N}$ & $\begin{array}{l}\text { Chi-square } \\
\text { (sig) }\end{array}$ & \multirow{8}{*}{$\begin{array}{l}\text { Sig: } *=\mathrm{p}<.05, * *=\mathrm{p}<.01 \text {, } \\
* * *=\mathrm{p}<.001 . \\
* \text { Standardized residuals } \\
\text { higher than } 2.0 \text { and lower } \\
\text { than }-\mathbf{2 . 0} \text { are statistically } \\
\text { significant }\end{array}$} \\
\hline \multicolumn{6}{|l|}{ Do you ever visit or invite at home: } \\
\hline - Friends & $72.5^{*}$ & 85.9 & 6065 & $137.1 * * *$ & \\
\hline - Relatives & 82.1 & 84.6 & 6106 & $4.9 *$ & \\
\hline \multicolumn{6}{|l|}{ In your leisure time, do you: } \\
\hline $\begin{array}{l}\text { - To the cinema, theatre, opera museums, } \\
\text { libraries or exhibitions? }\end{array}$ & $60.8 *$ & $81.6^{*}$ & 5657 & $262.4^{* * *}$ & \\
\hline & $65.0 *$ & $86.2 *$ & 5985 & $324.6 * * *$ & \\
\hline $\begin{array}{l}\text { To go out with friends for a walk, to go } \\
\text { shopping or to watch sporting events? }\end{array}$ & $71.4^{*}$ & 84.9 & 5991 & $132.4 * * *$ & \\
\hline - To take part in sporting activities? & $38.4^{*}$ & $59.2 *$ & 4030 & $182.1 * * *$ & \\
\hline $\begin{array}{l}\text { - To take part in clubs, religious, trade } \\
\text { union or political activities? }\end{array}$ & 43.1 & 45.9 & 7255 & n.s. & \\
\hline
\end{tabular}


Table 4. The predictors for the mobile phone ownership (Logistic Regression Analysis) Predictors Exp (B) + Sig. $\quad 95 \%$ C.I. for $\operatorname{Exp}(B)$ Lower Upper

\section{Sex}

- Male

- Female

1

Age

$-14-17$

$-18-24$

- 25-44

$-44-64$

- 65+

$.640 * * *$

.546

.751

Education

- Low

- Medium

$1 * * *$

1.571

.949

.902

2.735

$.401 * * *$

.613

1.468

$.224^{* * *}$

.146

.612

.345

- High

$1 * * *$

$1.538 * * *$

1.273

1.859

$1.791 * * *$

1.431

2.242

Family type

- Single

- Couple, no children

$1 * *$

$\begin{array}{lll}1.430 * * * & 1.155 & 1.771\end{array}$

$\begin{array}{lll}1.286^{*} & 1.039 & 1.592\end{array}$

$\begin{array}{lll}1.245 & .859 & 1.804\end{array}$

- One parent with children

.869

.670

1.199

City size (inhabitants)

- Up to 5000

- 5 000-10000

1

$-10000-30000$

1.059

.742

1.512

.904

.653

1.250

- $30000-100000$

.928

.680

1.266

$-100000-250000$

$.713^{*}$

.520

.979

- 250 000-500 000

.621

1.257

- 500000 or more

1.007

.749

1.354

Country

- Italy

- France

- Germany

- United Kingdom

- Spain

$1 * * *$

$168 * * *$

.124

.226

$.177 * * *$

.134

.234

$.377 * * *$

.268

.530

$.280 * * *$

.204

.384

Sociability ( $0=$ Never, $1=$ Yes $)$

Do you ever visit or invite at home:

- Friends

$1.383 * *$

1.128

1.697

- Relatives

1.212

.981

1.498

In your leisure time, do you:

- To the cinema etc.?

$1.410^{* *}$

1.118

1.779

- To restaurants, etc.?

$1.781^{* * *}$

1.408

2.253

.891

.710

1.118

$1.299 * *$

1.072

1.573

- To take part in sporting activities?

$.767^{* *}$

.639

.921

Sig. $=^{*}=\mathrm{p}<.05,{ }^{* *}=\mathrm{p}<.01,{ }^{* * *}=\mathrm{p}<.001$. 